\title{
Article \\ Effect of Leaf Age, Leaf Segments and Surface Treatments on Pathogenicity Levels of Colletotrichum sublineola in Sorghum and Johnson Grass
}

\author{
Ezekiel Ahn (D), Farrell Fan and Clint Magill *(D)
}

check for updates

Citation: Ahn, E.; Fan, F.; Magill, C. Effect of Leaf Age, Leaf Segments and Surface Treatments on Pathogenicity Levels of Colletotrichum sublineola in Sorghum and Johnson Grass. Crops 2021, 1, 111-117. https://doi.org/ $10.3390 /$ crops 1030011

Academic Editor: II-Ryong Choi

Received: 6 September 2021

Accepted: 21 October 2021

Published: 26 October 2021

Publisher's Note: MDPI stays neutral with regard to jurisdictional claims in published maps and institutional affiliations.

Copyright: (c) 2021 by the authors. Licensee MDPI, Basel, Switzerland. This article is an open access article distributed under the terms and conditions of the Creative Commons Attribution (CC BY) license (https:/ / creativecommons.org/licenses/by/ $4.0 /)$.
Department of Plant Pathology \& Microbiology, Texas A\&M University, College Station, TX 77843, USA; eja85@tamu.edu (E.A.); farrellfan88@gmail.com (F.F.)

* Correspondence: c-magill@tamu.edu

\begin{abstract}
Colletotrichum sublineola is a casual pathogen of sorghum anthracnose. Sorghum pathologists often need to conduct evaluations for anthracnose resistance in large scale which are expensive and labor intensive. As a solution, an excised-leaf assay has been used, but whether or not leaf age, position or region affects pathogenicity scores has not previously been evaluated. Essentially, in an excised-leaf assay, is response to $C$. sublineola over all or part of a leaf blade identical? To get an answer, three sorghum and one Johnson grass cultivars were tested. The top five leaves were inoculated at the apex, mid-leaf and base of each leaf blade. Results show nearly no effect of leaf age to pathogenicity level within the top five leaves. Furthermore, in order to evaluate any protective role of leaf wax to C. sublineola, the wax was disrupted by simply wiping the leaf surface by a thumb, or as an alternative method, leaf surface tension was reduced by submerging leaves into $2 \%$ TWEEN 20 before inoculation. Compared to control, wiped leaves increased pathogenicity scores on the leaf blade and midrib in two of three sorghum cultivars, but $2 \%$ TWEEN 20-treated leaves had only minimal changes in pathogenicity level compared to controls.
\end{abstract}

Keywords: sorghum; Johnson grass; Colletotrichum sublineola; waxiness; leaf age; surface tension

\section{Introduction}

Sorghum (Sorghum bicolor) is the fifth most important cereal grown worldwide [1]. It is a drought-resilient crop grown extensively in semiarid regions/areas of the world [2]. Sorghum is consistently exposed to abiotic and biotic stresses. One of the major sorghum diseases, anthracnose, is caused by Colletotrichum sublineola (equivalent, C. sublineolum). C. sublineola infects all aerial parts of sorghum including leaf and stalk [3]. In order to identify new sources of resistance to anthracnose, sorghum pathologists have been surveying many sorghum accessions through field and greenhouse inoculation, but conducting a mass evaluation is often expensive since it requires time, large spaces and extensive labor [4]. An excised-leaf assay offers several advantages in screening sorghum for anthracnose resistance, including saving time, labor, space and expenses [4]. The first question to be addressed was whether leaf age, based on position on the plant, has an effect on disease severity level in response to $C$. sublineola. Physiological characteristics such as leaf age could affect the outcomes of an excised assay. As an example, in wheat (Triticum aestivum), younger plants had significantly greater disease severity than older plants against Puccinia striiformis f. sp. tritici, the causal agent of wheat stripe rust, and this effect was also greater on upper leaves [5].

The second question addressed was comparing disease severity level for leaf segments taken from the apex, center and base to determine if all parts are equally responsive to C. sublineola. To answer these questions, three sorghum cultivars and one Johnson grass (Sorghum halepense) cultivar, a wild relative of sorghum, were tested. Segments from the 
apex, mid-leaf and base of the top five leaves from plants grown to the 8-leaf stage were inoculated with three isolates of C. sublineola and scored using a standard 1-5 scale [6].

In a previous study, there was an attempt to explore potential correlations of leaf blade and midrib thickness with the response to C. sublineola in the similar cultivars [7]. Unlike midrib thickness, that study did not find any meaningful correlation between leaf blade thickness and pathogenicity level [7]. Leaf thickness is an important morphological trait that plays significant roles in leaf and plant functioning, resource acquisition, and yield potential [8,9]. It has been shown that Colletotrichum spp., including C. camelliae, C. fructicola and C. sublineola, penetrate directly through the cuticle and epidermal cell wall of the hosts [10,11]. Lu et al. [11] found that the thick cuticle of tea plants (Camellia sinensis) prevents penetration of microorganisms and the feeding insects including anthracnose causing pathogens $C$. camelliae and C. fructicola. Cuticular wax ultrastructure and chemical composition differ with plant species, developmental stage and physiological state [12]. It protects the plant against environmental stresses, including desiccation, UV radiation, microorganisms and insects [12]. Although wax has been described as a barrier for other Colletotrichum spp. on other hosts including tomato (Solanum lycopersicum) [13] and peppers (Capsicum annuum) [14], there is also evidence that a component of the wax aids in anthracnose infection of Medicago truncatula where mutants of a gene named inhibitor of rust germ tube differentation 1 and a Cys(2)His(2) zinc finger transcription factor (irg1/palm1) led to reduced spore differentiation of anthracnose and nonhost rust pathogens [15].

To our knowledge, no investigation of the role of wax that addresses the interaction of sorghum or Johnson grass leaves with C. sublineola has previously been conducted.

Here, two different methods were used to remove or alter wax on sorghum and Johnson grass leaves. In the first, wax was removed by rubbing a thumb on the adaxial part of leaf blade and midrib. As an alternative, leaf surface tension was greatly reduced by submerging leaves into $2 \%$ TWEEN 20, a wetting agent, for $20 \mathrm{~s}$. The responses to C. sublineola between groups with different treatments including control were compared using an excised-leaf assay.

\section{Materials and Methods}

For comparisons of susceptibility level between younger and older sorghum leaves to C. sublineola, three sorghum cultivars, BTx623, PI609251, and TAM428 and a Johnson grass cultivar, SH1152 were used. BTx623 is a susceptible parent that was used in mapping Cg1 in field trials for response to C. sublineolum isolate 430BB-85 [16]. PI609251 is originally from Mali and was selected because of its susceptibility to all anthracnose-causing pathotypes from Puerto Rico, Texas, Georgia and Arkansas [17]. TAM428 is susceptible to ten different pathotypes from Texas, Arkansas and Puerto Rico [18].

Plants were grown in a Conviron growth chamber (Conviron, Manitoba, Winnipeg, Canada) at $23{ }^{\circ} \mathrm{C}$ with $65 \%$ humidity. Plants were planted into 2-gallon plastic pots filled with Sungro professional growing mix (Sun Gro Horticulture, Agawam, MA, USA). At the 8-leaf stage, the top five leaves were used for disease response assays. Leaves were numbered from top to the bottom as 1 through 5 . Immediately after detachment, leaf blade segments were taken near the apex, near the base, and half-way between the two points and used for excised-leaf assays.

For comparisons of pathogenicity levels resulting from different treatments for waxiness on leaf surface, nearly the same procedures were used as described above, but only all 1-5 leaves were used. A physical technique, rubbing with a thumb for $30 \mathrm{~s}$, was applied to all adaxial surfaces of each detached leaf. As another method, leaf surface tension was greatly reduced by submerging leaves into 2\% TWEEN 20 (Agdia, Elkhart, IN, USA) for $20 \mathrm{~s}$. After briefly washing leaves with $5 \%$ bleach, all detached leaves were air dried for the next step.

For the excised-leaf assay, the method described in Ahn et al. [6] was used. Three strains of $C$. sublineola were used, including AMP27 which has been used as a mixture with other isolates to map resistance in the progeny of sorghum crosses [17] in addition to FSP35 
and FSP53, both of which have been shown to vary in virulence to sorghum and Johnson grass cultivars [6]. All three were originally isolated from sorghum. For preparation of inoculum, the method described by Prom et al. [4] was used. In brief, 10-14-day old cultures of $C$. sublineola grown on half strength potato dextrose agar (PDA) medium (Becton, Dickinson and Co., Franklin Lakes, NJ, USA) were scraped to remove fungal biomass and spores from the plate. After filtration through four layers of cheesecloth, the spores were diluted to a final concentration of $\sim 1 \times 10^{6}$ conidia $/ \mathrm{mL}$. Excised leaf pieces, placed adaxial side upon the agar surface, were inoculated by placing $5 \mu \mathrm{L}$ of the spore suspension on pre-marked spots on the leaf blade for leaf age and site inoculation experiments and also on the midrib for the waxiness experiment. As described in Prom et al. [4], the PDA plates were incubated at $28{ }^{\circ} \mathrm{C}$ for $96 \mathrm{~h}$ in the dark. Excised leaves were observed under an Olympus BX60 microscope (Olympus Co., Shinjuku, Tokyo, Japan) at $96 \mathrm{~h}$ post-inoculation. Susceptibility was scored using a 1-5 scale: 1 . fully resistant without visible fungal infection, 2. fungal germ tube formed, 3. fungal bed formed with some imperfectly formed acervuli, 4. 1-5 acervuli perfectly formed, 5. more than 5 acervuli perfectly formed [6].

After conducting the leaf age and site of inoculation experiments, the plants were cut back and allowed to regrow for the waxiness experiments. In this way, we could also compare disease severity level vs. plant age in addition to comparing disease severity level between leaves. After cutting the plants, Osmocote fertilizer (Scotts miracle-gro, Marysville, $\mathrm{OH}, \mathrm{USA}$ ) was added as recommended to the pots in order to recharge nutrients. Each experiment was conducted at least three times.

For statistical analysis, Wilcoxon's all possible pair comparisons test and KruskalWallis one-way analysis of variance were conducted by JMP Pro 15 (SAS Institute, Cary, NC, USA) to compare median pathogenicity scores between leaves $1-5$, inoculation site (apex, middle and base), and combinations of the two, creating 15 different groups in each cultivar. For comparing the two waxiness treatments with control and effects before and after cutting, Wilcoxon's all possible pair comparisons test was applied as well.

\section{Results}

3.1. Leaf Age and Location Affected Pathogenicity Severity Level in Cultivar/Isolate Specific Combinations

As expected, the disease rating scores were different for the different isolates (Table 1). Based on the Kruskal-Wallis and Wilcoxon signed rank tests, no difference was detected for BTx623 among the first to the fifth leaves, but inoculations at the base of the leaf resulted in somewhat higher scores for FSP35. In the case of PI609251, the fifth leaf gave a lower score for AMP 27 and the first higher for FSP53. Additionally, a small increase was noted when inoculation with FSP53 was at the base of the leaf. Likewise, TAM428 which overall had high susceptibility scores showed lower values when inoculated with AMP27 on the third leaf and a higher score at the base of the leaf when inoculated with FSP53. The Johnson grass cultivar resulted in lower scores for each isolate on the fifth leaf as well as the leaf for FS35, but no differences were detected among base, apex or mid-leaf inoculations. In these cases, however, the responses elicited were lower than median score 3 which based on failure to produce acervuli is the cut-off for host susceptibility, so the slight effects observed for leaf age or position would not change the ultimate disease response evaluations.

\subsection{Physical Removal of Wax Increased Pathogenicity Levels in Some Cases}

Results of the attempts to alter infection rate by physically disrupting leaf wax or using a wetting agent are shown in Table 2. Often the outcomes of the two treatments were not significantly different compared to control, but a few cases showed clear differences between control and treated group(s). In TAM428 inoculated with spores from the AMP27, FSP35 and FSP53 isolates, the highest score was associated with rubbing the leaf blade just leaf prior to inoculation (Table 2). 
Table 1. Comparisons of pathogenicity severity level in host plant to C. sublineola isolates for different leaves and locations. Median values are shown. Values in a column with the same letter(s) are not significantly different at the probability level of $5 \%$ based on Wilcoxon signed rank test. $n=15$ for the 1st-5th leaves and $n=25$ for leaf position.

\begin{tabular}{|c|c|c|c|c|}
\hline $\begin{array}{l}\text { Leaf \# and } \\
\text { Position }\end{array}$ & BT $\times 623$ & PI609251 & TAM428 & SH1152(JG) \\
\hline \multicolumn{5}{|c|}{ AMP27 } \\
\hline 1st leaf & $2 a$ & $2 \mathrm{ab}$ & $5 \mathrm{ab}$ & $2 \mathrm{ab}$ \\
\hline 2nd leaf & $2 a$ & $2 a$ & $5 \mathrm{ab}$ & $2 a$ \\
\hline 3rd leaf & $2 a$ & $2 a b$ & $5 \mathrm{~b}$ & $2 \mathrm{ab}$ \\
\hline 4th leaf & $2 a$ & $2 a b$ & $5 a b$ & $2 a b$ \\
\hline 5 th leaf & $2 a$ & $1 \mathrm{~b}$ & $5 a$ & $1 \mathrm{~b}$ \\
\hline Apex & $2 \mathrm{a}$ & $2 \mathrm{a}$ & $5 a$ & $2 \mathrm{a}$ \\
\hline Mid-leaf & $2 \mathrm{a}$ & $2 a$ & $5 a$ & $2 a$ \\
\hline Base & $2 \mathrm{a}$ & $2 \mathrm{a}$ & $5 a$ & $2 a$ \\
\hline \multicolumn{5}{|c|}{ FSP35 } \\
\hline 1st leaf & $2 a$ & $2 a$ & $2 a$ & $2 \mathrm{ab}$ \\
\hline 2nd leaf & $2 \mathrm{a}$ & $2 a$ & $2 a$ & $3 a$ \\
\hline 3rd leaf & $2 \mathrm{a}$ & $2 a$ & $2 a$ & $2 a b$ \\
\hline 4th leaf & $2 a$ & $2 a$ & $2 a$ & $2 b$ \\
\hline 5 th leaf & $2 a$ & $1 \mathrm{a}$ & $2 a$ & $2 b$ \\
\hline Apex & $2 \mathrm{a}$ & $2 a$ & $2 a$ & $2 a$ \\
\hline Mid-leaf & $2 a b$ & $2 \mathrm{a}$ & $2 a$ & $2 a$ \\
\hline Base & $2 \mathrm{~b}$ & $2 \mathrm{a}$ & $2 \mathrm{a}$ & $2 \mathrm{a}$ \\
\hline \multicolumn{5}{|c|}{ FSP53 } \\
\hline 1st leaf & $2 a$ & $2 a$ & $2 a$ & $2 a$ \\
\hline 2nd leaf & $2 a$ & $2 \mathrm{ab}$ & $2 a$ & $2 b$ \\
\hline 3rd leaf & $2 \mathrm{a}$ & $2 b$ & $2 a$ & $2 a$ \\
\hline 4th leaf & $2 a$ & $2 b$ & $2 a$ & $2 b$ \\
\hline 5 th leaf & $2 a$ & $2 b$ & $2 a$ & $2 a b$ \\
\hline Apex & $2 a$ & $1 \mathrm{~b}$ & $2 a$ & $2 a$ \\
\hline Mid-leaf & $2 \mathrm{a}$ & $2 b$ & $2 a b$ & $2 a$ \\
\hline Base & $2 a$ & $2 a$ & $2 b$ & $2 a$ \\
\hline
\end{tabular}

For two combinations, the results would change the overall response to susceptible. BTx623 and PI609251 showed higher severity in rubbed leaf blade samples when inoculated with FSP53 and AMP27, respectively. TAM428 also showed higher scores in rubbed leaf blade samples against all the three tested strains. On midrib, control leaves showed statistically resistant responses compared to rubbing or $2 \%$ TWEEN 20 treated samples in some cases; for example, rubbed and Tween 20 treated BTx623 samples were more susceptible to FSP53 on midrib. In most of the host-pathogen combinations, samples treated with $2 \%$ TWEEN 20 grouped with the corresponding control.

\subsection{Cut Back and Regrown BTx623 and PI609251 Sorghum Plants Were More Susceptible to C. sublineola Infection}

Even though it is not one of the original questions that was addressed, the regrown sorghum lines BTx623 and PI609251 showed higher susceptibility to all three isolates tested based on Wilcoxon signed-rank test ( $p$-value <0.05) (Table 3). TAM428, on the other hand, showed either no difference (FSP53) or opposite results (AMP27 and FSP35) between the two groups. SH1152 followed the same patterns shown in BTx623 and PI609251 with higher susceptibility for regrown plants when inoculated with AMP27 and FSP35, but the outcome was the opposite for the FSP53 inoculation. 
Table 2. Comparisons of pathogenicity level in host plant to C. sublineola isolates for physical removal of wax and Tween 20 treatment. Median values are shown. Values in a column with the same letter(s) are not significantly different at the probability level of $5 \%$ based on Wilcoxon signed rank test. Leaf blade and midrib were analyzed separately. $n=10$ for BTx623, PI609251 and TAM428. $n=6$ for SH1152.

\begin{tabular}{|c|c|c|c|c|}
\hline Treatment \& Region & BT $\times 623$ & PI609251 & TAM428 & SH1152(JG) \\
\hline \multicolumn{5}{|c|}{ AMP27 } \\
\hline Control leaf blade & $5 \mathrm{a}$ & $5 \mathrm{a}$ & $2.67 \mathrm{a}$ & $2.5 \mathrm{a}$ \\
\hline Rubbed leaf blade & $5 a$ & $5 b$ & $4.33 \mathrm{~b}$ & $2.33 \mathrm{a}$ \\
\hline Tween 20 leaf blade & $4.83 \mathrm{a}$ & $5 \mathrm{ab}$ & $3 a b$ & $4 \mathrm{a}$ \\
\hline Control midrib & $2.83 \mathrm{ab}$ & $2.83 \mathrm{a}$ & $1.17 \mathrm{a}$ & $1.33 \mathrm{a}$ \\
\hline Rubbed midrib & $3.67 \mathrm{a}$ & $4.33 \mathrm{a}$ & $1.67 \mathrm{~b}$ & $1.33 \mathrm{a}$ \\
\hline Tween 20 midrib & $2.17 \mathrm{~b}$ & $2.67 \mathrm{a}$ & $1.33 \mathrm{a}$ & $1 \mathrm{a}$ \\
\hline \multicolumn{5}{|c|}{ FSP35 } \\
\hline Control leaf blade & $2.33 \mathrm{ab}$ & $4 \mathrm{a}$ & $1.33 \mathrm{a}$ & $1.33 \mathrm{a}$ \\
\hline Rubbed leaf blade & $3.83 \mathrm{a}$ & $5 \mathrm{a}$ & $2.5 \mathrm{~b}$ & $1.17 \mathrm{a}$ \\
\hline Tween 20 leaf blade & $1.5 \mathrm{~b}$ & $4.83 \mathrm{a}$ & $1.5 \mathrm{ab}$ & $1 \mathrm{a}$ \\
\hline Control midrib & $1.33 \mathrm{a}$ & $1.83 \mathrm{a}$ & $1 \mathrm{a}$ & $1.33 \mathrm{a}$ \\
\hline Rubbed midrib & $1.5 \mathrm{a}$ & $1.83 \mathrm{a}$ & $1 \mathrm{a}$ & $1.17 \mathrm{a}$ \\
\hline Tween 20 midrib & $1 \mathrm{a}$ & $2.33 \mathrm{a}$ & $1 \mathrm{a}$ & $1 \mathrm{a}$ \\
\hline \multicolumn{5}{|c|}{ FSP53 } \\
\hline Control leaf blade & $4.5 \mathrm{ab}$ & $5 \mathrm{a}$ & $1.83 \mathrm{a}$ & $2.5 \mathrm{a}$ \\
\hline Rubbed leaf blade & $5 c$ & $5 \mathrm{a}$ & $4.67 \mathrm{~b}$ & $3.17 \mathrm{a}$ \\
\hline Tween 20 leaf blade & $5 \mathrm{bc}$ & $5 \mathrm{a}$ & $2.17 \mathrm{a}$ & $2.67 \mathrm{a}$ \\
\hline Control midrib & $1.33 \mathrm{a}$ & $3.17 \mathrm{a}$ & $1 \mathrm{a}$ & $1 \mathrm{a}$ \\
\hline Rubbed midrib & $2.33 \mathrm{~b}$ & $3.17 \mathrm{a}$ & $1.33 \mathrm{a}$ & $1 \mathrm{a}$ \\
\hline Tween 20 midrib & $3.67 \mathrm{~b}$ & $3 a$ & $1.33 \mathrm{a}$ & $1 \mathrm{a}$ \\
\hline
\end{tabular}

Table 3. Comparisons of pathogenicity level in host plant to C. sublineola isolates between newly grown and cut back and regrown plants. Median values are shown. ${ }^{*}=p$-value $<0.05$, ${ }^{* *}=p$-value $<0.001$ and ${ }^{* * *}=p$-value $<0.0001$ based on Wilcoxon signed rank test. $n=75$ for newly grown plants while $n=6$ to 10 for cut back and regrown plants in all cultivars.

\begin{tabular}{|c|c|c|c|c|}
\hline $\begin{array}{l}\text { New or } \\
\text { Regrown }\end{array}$ & ВТх623 & PI609251 & TAM428 & SH1152(JG) \\
\hline \multicolumn{5}{|c|}{ AMP27 } \\
\hline New & $2 * *$ & $2 * * *$ & $5^{* * *}$ & $2 * *$ \\
\hline Regrown & $5^{* *}$ & $5^{* * *}$ & $2.67^{* * *}$ & $2.5^{* *}$ \\
\hline \multicolumn{5}{|c|}{ FSP35 } \\
\hline New & $2 *$ & $2 *$ & $2 * * *$ & $2^{* *}$ \\
\hline Regrown & $2.33 *$ & $4^{*}$ & $1.33^{* * *}$ & $1.33^{* *}$ \\
\hline \multicolumn{5}{|c|}{ FSP53 } \\
\hline New & $2^{* * *}$ & $2^{* * *}$ & 2 & 2 \\
\hline Regrown & $4.5^{* * *}$ & $5^{* * *}$ & 1.83 & 2.5 \\
\hline
\end{tabular}

\section{Discussion}

This study revealed that there can be minor effects of leaf age to pathogenicity level in some sorghum and Johnson grass cultivars to C. sublineola. The first leaf of PI609251 was more susceptible than lower leaves when inoculated with FSP53 (Table 1). In wheat, upper leaves were more susceptible to Puccinia striiformis [5]. However, unlike wheat responding to Puccinia striiformis, the responses differed in sorghum depending on specific cultivar and C. sublineola isolates. The results indicate that the excised-leaf assay can be used in any part of the leaf blade but that it is best to use the same leaf and site of inoculation. 
Furthermore, the results reveal a potential protective role of wax on both leaf blade and midrib, but the outcomes vary depending on host cultivar and C. sublineola isolates. A simple wax disruption technique made some excised leaf samples highly susceptible. On the other hand, although 2\% TWEEN 20 treated samples had slightly higher pathogenicity scores in some cases, this treatment was not as effective as simply rubbing the leaf surface. Differences in diseases severity level for leaves taken from the same plants before and after regrowth following cut back may reflect different environmental conditions at the time of inoculation and/or effects of host defense genes showing differential expression as a result of wounding. Again, further research is warranted.

Author Contributions: Conceptualization, E.A. and C.M.; methodology, E.A.; validation, E.A. and F.F.; formal analysis, E.A.; investigation, E.A. and F.F.; resources, C.M.; data curation, E.A. and F.F.; writing-original draft preparation, E.A.; writing-review and editing, C.M.; supervision, C.M.; project administration, C.M.; funding acquisition, C.M. All authors have read and agreed to the published version of the manuscript.

Funding: This study was funded by AFRI, NIFA, USDA (grant number 20156800423492).

Institutional Review Board Statement: Not applicable.

Informed Consent Statement: Not applicable.

Data Availability Statement: Not applicable.

Conflicts of Interest: No potential conflict of interest relevant to this article was reported.

\section{References}

1. Doggett, H. Sorghum, 2nd ed.; Longman Scientific: Essex, UK, 1988; ISBN 0-582-46345-9.

2. Rakshit, S.; Hariprasanna, K.; Gomashe, S.; Ganapathy, K.N.; Das, I.K.; Ramana, O.V.; Dhandapani, A.; Patil, J.V. Changes in area, yield gains, and yield stability of sorghum in major sorghum-producing countries, 1970 to 2009. Crop Sci. 2014, 54, 1571-1584. [CrossRef]

3. Buiate, E.A.S.; Xavier, K.V.; Moore, N.; Torres, M.F.; Farman, M.L.; Schardl, C.L.; Vaillancourt, L.J. A comparative genomic analysis of putative pathogenicity genes in the host-specific sibling species Colletotrichum graminicola and Colletotrichum sublineola. BMC Genom. 2017, 18, 67. [CrossRef] [PubMed]

4. Prom, L.K.; Cuevas, H.E.; Isakeit, T.; Droleskey, R. Excised leaf method for high volume evaluation of Sorghum germplasm for resistance against Colletotrichum sublineolum. Plant Pathol. J. 2016, 15, 11-16. [CrossRef]

5. Farber, D.H.; Mundt, C.C. Effect of plant age and leaf position on susceptibility to wheat stripe rust. Phytopathology 2016, 107, 412-417. [CrossRef] [PubMed]

6. Ahn, E.; Prom, L.K.; Odvody, G.; Magill, C. Defense responses against the sorghum anthracnose pathogen in leaf blade and midrib tissue of johnsongrass and sorghum. Physiol. Mol. Plant Pathol. 2019, 106, 81-86. [CrossRef]

7. Ahn, E.; Odvody, G.; Prom, L.K.; Magill, C. Leaf angle distribution in Johnsongrass, leaf thickness in sorghum and Johnsongrass, and association with response to Colletotrichum sublineola. Sci. Rep. 2020, 10, 22320. [CrossRef] [PubMed]

8. Vile, D.; Garnier, É.; Shipley, B.; Laurent, G.; Navas, M.-L.; Roumet, C.; Lavorel, S.; Díaz, S.; Hodgson, J.G.; Lloret, F.; et al. Specific leaf area and dry matter content estimate thickness in laminar leaves. Ann. Bot. 2005, 96, 1129-1136. [CrossRef] [PubMed]

9. Liu, C.-G.; Zhou, X.-Q.; Chen, D.-G.; Li, L.-J.; Li, J.-C.; Chen, Y.-D. Natural variation of leaf thickness and its association to yield traits in indica rice. J. Integr. Agric. 2014, 13, 316-325. [CrossRef]

10. Wharton, P.S.; Julian, A.M.; O'Connell, R.J. Ultrastructure of the infection of sorghum bicolor by Colletotrichum sublineolum. Phytopathology 2001, 91, 149-158. [CrossRef] [PubMed]

11. Lu, Q.; Wang, Y.; Li, N.; Ni, D.; Yang, Y.; Wang, X. Differences in the characteristics and pathogenicity of Colletotrichum camelliae and C. fructicola isolated from the tea plant [Camellia sinensis (L.) O. Kuntze]. Front. Microbiol. 2018, 9, 3060. [CrossRef] [PubMed]

12. Lewandowska, M.; Keyl, A.; Feussner, I. Wax biosynthesis in response to danger: Its regulation upon abiotic and biotic stress. New Phytol. 2020, 227, 698-713. [CrossRef] [PubMed]

13. Cruickshank, R.H. The influences of epicuticular wax disruption and cutinase resistance on penetration of tomatoes by Colletotrichum gloeosporioides. J. Phytopathol. 1995, 143, 519-524. [CrossRef]

14. Oh, B.J.; Kim, K.D.; Kim, Y.S. Effect of cuticular wax layers of green and red pepper fruits on infection by Colletotrichum gloeosporioides. J. Phytopathol. 1999, 147, 547-552. [CrossRef]

15. Uppalapati, S.R.; Ishiga, Y.; Doraiswamy, V.; Bedair, M.; Mittal, S.; Chen, J.; Nakashima, J.; Tang, Y.; Tadege, M.; Ratet, P.; et al. Loss of abaxial leaf epicuticular wax in Medicago truncatula irg1/palm1 mutants results in reduced spore differentiation of anthracnose and nonhost rust pathogens. Plant Cell. 2012, 24, 353-370. [CrossRef] [PubMed] 
16. Ramasamy, P.; Menz, M.; Mehta, P.; Katilé, S.; Gutierrez-Rojas, L.; Klein, R.R.; Klein, P.E.; Prom, L.K.; Schlueter, J.A.; Rooney, W.L.; et al. Molecular mapping of Cg1, a gene for resistance to anthracnose (Colletotrichum sublineolum) in sorghum. Euphytica 2009, 165, 597-606. [CrossRef]

17. Cuevas, H.E.; Prom, L.K.; Erpelding, J.E. Inheritance and molecular mapping of anthracnose resistance genes present in sorghum line SC112-14. Mol. Breed. 2014, 34, 1943-1953. [CrossRef]

18. Prom, L.K.; Perumal, R.; Erattaimuthu, S.R.; Little, C.R.; No, E.G.; Erpelding, J.E.; Rooney, W.L.; Odvody, G.; Magill, C. Genetic diversity and pathotype determination of Colletotrichum sublineolum isolates causing anthracnose in sorghum. Eur. J. Plant Pathol. 2012, 133, 671-685. [CrossRef] 